\title{
Se actualiza el Plan Nacional de Patrimonio Industrial
}

\begin{abstract}
El Plan Nacional de Patrimonio Industrial fue aprobado en 2001 con el objetivo de crear una metodología propia en la gestión del patrimonio industrial'. Pasados diez años desde su aprobación, la ampliación del concepto de bien industrial y otras consideraciones, como los nuevos criterios de valoración y selección, requisitos para la intervención o gestión, los cambios legislativos en la materia o la necesidad de elaborar un inventario a escala nacional, hicieron necesaria la revisión del Plan, viendo la luz dicho documento el pasado mes de marzo.
\end{abstract}

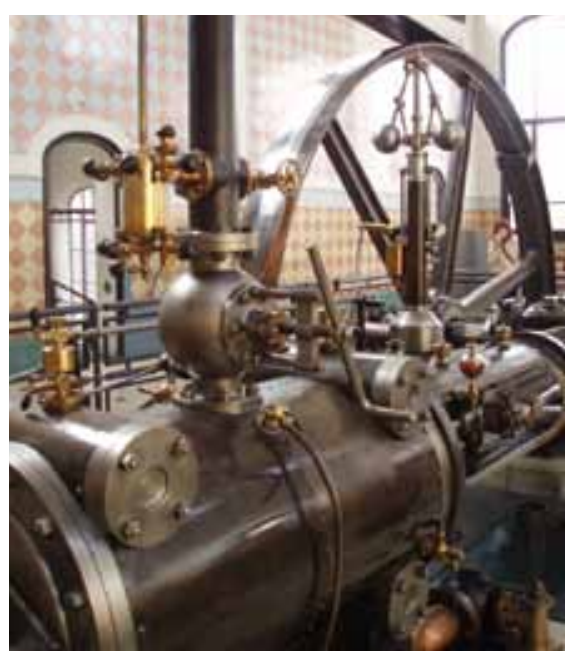

Máquina de vapor de la antigua fábrica textil Aymerich, Amat i Jover en Tarrasa, actual sede del Museo Nacional de la Ciencia y la Tecnología de Cataluña. Foto: Julián Sobrino Simal

Estamos de suerte. El panorama que ofrece hoy día el patrimonio industrial español es bastante más esperanzador que el de hace una década, cuando se puso en marcha el primer Plan Nacional de Patrimonio Industrial. ¿Qué ha sucedido? pues, sencillamente, lo que era de esperar, que las administraciones públicas, que tienen a la cultura entre sus competencias, se implicaran en una estrategia que, de manera descoordinada pero eficaz, ya había sido asumida y puesta en marcha por la sociedad civil.

En esta última década han proliferado las asociaciones de defensa y estudio del patrimonio industrial, de ámbito local, regional o estatal; nos encontramos con numerosos medios electrónicos de difusión, webs-sites, blogs; se han multiplicado los encuentros científicos, jornadas, seminarios o congresos; las líneas de investigación sobre este patrimonio han llegado a las universidades, asignaturas optativas, grupos de investigación, programas de doctorado y master; contamos con una presencia constante en los medios de comunicación ya sea como resultado de campañas reivindicativas, rehabilitaciones de espacios industriales 0 programas especificos relacionados con el turismo industrial; se han producido revisiones legislativas de gran calado como es la de la inclusión del patrimonio industrial en la nueva Ley de Patrimonio Histórico de Andalucia; se ha generado una oferta con estructura de mercado en torno a los museos, las exposiciones o los itinerarios; y actualmente disponemos de una nueva conciencia pública y ciudadana acerca del valor que tiene la "cultura del trabajo" ya sea como memoria, como recurso o como las dos cosas.

La oportunidad que ha supuesto la revisión del Plan Nacional de Patrimonio Industrial, en la que Andalucia ha tenido un papel relevante, va a permitir contar con un nuevo marco de referencia en aspectos básicos como son la visibilidad del nuevo espacio legislativo, la definición conceptual de este patrimonio, sus categorias de protección o la identificación de los riesgos. En cuanto a los aspectos metodológicos hay que tener en cuenta los nuevos criterios de valoración y selección, los requisitos para la intervención o la gestión de los proyectos. Respecto a la programación de este Plan deben ser reflejados sus planteamientos en conservación preventiva, documentación, investigación o difusión. $Y$ algo tan interesante, en estos momentos de dificultades econó- micas, como es el contar con un estudio económico-financiero realista, junto a unos mecanismos de control y seguimiento de las actuaciones. Debe ser destacado el esfuerzo por superar anteriores carencias, quizás la más llamativa era la de la objetualización del patrimonio industrial en su concreción más arquitectónica. Ahora contamos con nuevos enfoques de carácter territorial y social. Apareciendo no sólo el patrimonio inmueble, sino, como era lógico, el mueble e inmaterial. Todo ello con unas intenciones de relacionar los bienes con sus paisajes, de conectar los valores entre si, de hacer emerger nuevos significados y de proponer programas de uso y no sólo de mera rehabilitación.

¿Qué nos falta? Pues ni más ni menos que la articulación de estas iniciativas en planes estratégicos de carácter estatal, autonómico y local que permitan una acción coordinada con vistas a la identificación de unos objetivos a medio plazo, de manera que para 2020 nos encontremos ya con una situación en la que los riesgos hayan desaparecido y el debate esté centrado en la mejora de los objetivos. Por tanto han de establecerse con claridad cinco líneas de actuación: 1 . Contar con un sistema de inventario estatal al que se añadan los registros autonómicos ya realizados, impulsando los que faltan por realizar; 2. Disponer de una estrategia museográfica que oriente las decisiones para este tipo de equipamientos; 3. Crear un espacio común de investigación y documentación; 4. Establecer alianzas con los sectores económicos implicados; 5. Generar un marco de formación y difusión estable y riguroso.

En la comunidad autónoma de Andalucia tenemos una excelente oportunidad para poner en marcha estas orientaciones bajo la fórmula de una Estrategia Andaluza para el Patrimonio Industrial de aquí a 2020.

\section{Julián Sobrino Simal}

Representante del IAPH en el Plan Nacional de Patrimonio Industrial

\section{Nota}

'Ver artículo relacionado en la sección Criterios de este número. 